\title{
UC ANR applies innovative research and programs to state's water scarcity
}

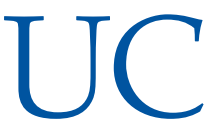

Division of Agriculture and Natural Resources (ANR) scientists have a long history of helping California agriculture remain productive in a varied climate. California's first drip irrigation, for example, was first introduced in the 1960s by ANR researchers in San Diego County. That spirit of innovation continues to this day.

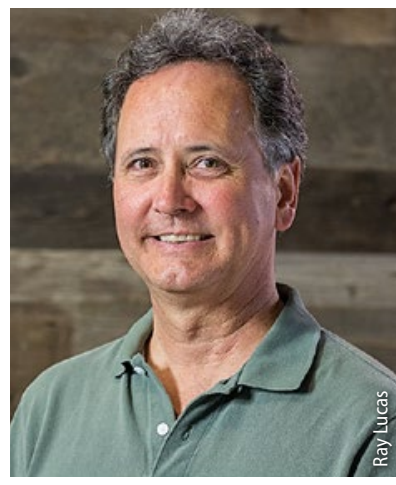

Doug Parker

Director

California Institute for Water

Resources

Leader

Water Quality, Quantity and

Security Strategic Initiative

Our work introducing and helping manage new, more efficient irrigation systems enables the state's growers to increase production in our water-scarce environment. This issue of California Agriculture highlights UC ANR's willingness to tackle new research areas of water management, specifically the use of recycled or reclaimed water.

Using recycled water for irrigation brings both new and familiar challenges to agriculture, with water quality and reliability as two major concerns. In their article "Chloride levels increase after 13 years of recycled water use in the Salinas Valley," Platts and Grismer find that while salinity levels increased less than predicted from using recycled water, chloride levels exceeded crop tolerance in some fields. The researchers furthered their work in the Salinas Valley, looking at soil water hydrologic factors controlling leaching. In the article "Rainfall leaching is critical for long-term use of recycled water in the Salinas Valley," they find that with moderate levels of salinity in irrigation water, soil salinity can reach a steady state.

While these studies focused on the Salinas Valley, the results have implications for using recycled water elsewhere. In the article "Recycled water causes no salinity or toxicity issues in Napa vineyards," Weber et. al. suggest that vineyards can thrive with recycled water under good irrigation management. Finally, the water section of this issue of California Agriculture includes a look at the use of new sensor technology to improve the efficiency of traditional surface water irrigation systems for alfalfa fields. This technology can increase water use efficiency and reduce potential water quality issues from endof-field runoff.

These articles demonstrate ANR's commitment to be an innovative source of solutions for California. To this end, ANR continues to support scientific inquiries that foster creativity. ANR's Strategic Vision 2025 serves as a guiding document for the Division and establishes the framework for how we respond to challenges that face the state. As part of this vision, we created five Strategic Initiatives to focus our research and extension programs: Water Quality, Quantity and Security; Endemic and Invasive Pests and Diseases; Sustainable Food Systems; Sustainable Natural Ecosystems; and Healthy Families and Communities. Each initiative seeks to capitalize on our science expertise to address issues of critical importance to California.

The Water Strategic Initiative, like the other four initiatives, is managed by a panel of scientists. The panel is responsible for creating and updating the initiative's 5-year strategic plan, recommending funding priorities for grants within ANR and making sure that adequate resources and staff are available to meet the plan's objectives (ucanr.edu/u. cfm?id=97).

In addition to the Water Strategic Initiative, ANR created the California Institute for Water Resources (CIWR), which coordinates and promotes waterrelated activities across the entire UC system. This institute works hand-in-hand with the ANR Water Strategic Initiative to expand our ability to respond to state needs. The CIWR has taken the lead at UC in organizing UC's drought-related research and outreach programs. Through its web portal (ciwr.ucanr. edu/) and Twitter feed (@ucanrwater), the CIWR

\section{This issue of California Agriculture highlights our willingness to tackle new research areas of water management.}

provides Californians with vital information on drought response resources, workshops and seminars, and media contacts and reports.

UC President Napolitano has appointed the CIWR to be the lead UC program on drought response and to liaison with Governor Brown's drought task force to bring UC resources to current drought issues. We seek to assist the governor's task force, and indeed all state agencies, with UC expertise and knowledge to help California through the drought. With water, as with other Division programs, ANR continues to seek and provide California with ideas and solutions based on science. 